\title{
Socio environmental impact in eco-architecture
}

\author{
I. Ibrahim \\ UAE University, $U A E$
}

\begin{abstract}
The interest of this paper is to focus on the social community and its built environment as an important part of creating ecological design, satisfying the community's social culture needs and achieving eco-architecture. The social impact assessment (SIA) is an important indicator in the age of information, communication technologies and globalization that affects the future of architecture. The social environment is different to the natural environment because it reacts in anticipation of change, but can adapt in reasoned ways to changing circumstances if this is part of the planning process, and there is the opportunity to participate in designing our future. This paper addresses itself to that modified challenge to achieve eco architecture. Firstly it attempts to define and clarify the SIA as a framework for the comprehensive understanding of environmental experience, regarding its variables and how it could be different depending on social cultures. Secondly it applies this idea to architectural projects that have won prizes at the AGKA awards for sustainable projects in developing countries, adopting the concept of our need to preserve the balance of nature. We consider Masdar, the zero carbon city in the UAE, in our case study with attention being given to the important relationship between physical design and social behaviour regarding eco-architecture.
\end{abstract}

Keywords: social impact, environmental, sustainable, architecture.

\section{Introduction}

Eco-architecture is sustainable architecture that involves a combination of values: aesthetic, environmental, social, political, and moral. It is about using one's imagination and technical knowledge to engage in the central aspect of the practice, designing and building in harmony with our environment. The smart architect thinks rationally about a combination of issues, including sustainability, durability, longevity, appropriate materials, and sense of place [1]. The challenge 
is finding the balance between environmental considerations and economic constraints. Consideration must be given to the needs of our communities and the ecosystem that supports them, and here we should mention that the SIA as a very important indicator for eco-architecture.

\section{Definition of eco-architecture}

First we have to define Ecology as the science of the relationship and interaction of living organisms with their inanimate (e.g. climate, soil) and their animate environment, as well as the study of resource and energy management in the biosphere and its sub-categories, and the study of the detrimental effects of modern civilization on the environment, with a view toward prevention or reversal through conservation [2]. Second we define what we mean by ecological building: as a movement in contemporary architecture. This movement aims to create environmentally friendly, energy-efficient buildings and developments by effectively managing natural resources. This entails passively and actively harnessing solar energy and using materials which, in their manufacture, application, and disposal, do the least possible damage to the so-called 'free resources': water, ground, and air.

\subsection{Eco-architecture principles}

\subsubsection{Understanding context}

Sustainable design begins with an intimate understanding of place. If we are sensitive to the nuances of place, we can inhabit without destroying it. Understanding place helps determine design practices such as solar orientation of a building on the site, preservation of the natural environment, and access to public transportation [3].

\subsubsection{Connecting with nature}

Whether the design site is a building in the inner city or in a more natural setting, connecting with nature brings the designed environment back to life. Effective design helps inform us of our place within nature.

\subsubsection{Understanding natural processes}

In nature there is no waste. In other words, natural systems are made of closed loops by working with living processes: we respect the needs of all species. Engaging processes that regenerate rather than deplete, we become more alive. Making natural cycles and processes visible brings the designed environment back to life.

\subsubsection{Understanding environmental impact}

Sustainable design attempts to have an understanding of the environmental impact of the design by evaluating the site, the embodied energy and toxicity of the materials, and the energy efficiency of the design, materials and construction techniques. Negative environmental impact can be mitigated through use of sustainably harvested building materials and finishes, materials with low toxicity 
in manufacturing and installation, and recycling building materials while on the job site. Embracing co-creative design processes, sustainable designers are finding it is important to listen to every voice. Collaboration with systems consultants, engineers and other experts happens early in the design process, instead of an afterthought. Designers are also listening to the voices of local communities.

\subsubsection{Understanding people}

Sustainable design must take into consideration the wide range of cultures, races, religions and habits of the people who are going to be using and inhabiting the built environment. This requires sensitivity and empathy to the needs of the people and the community.

\subsection{Environmental and social sustainable architecture}

There are five principles of an environmental architecture (Fisher, AIA, November, 1992 [4]): the first is a healthful interior environment. All possible measures are to be taken to ensure that materials and building systems do not emit toxic substances and gasses into the interior atmosphere and additional measures are to be taken to clean and revitalize the interior air with filtration and plantings. The second principle is energy efficiency. All possible measures are to be taken to ensure that the building's use of energy is minimal, cooling, heating and lighting systems are to use methods and products that conserve or eliminate energy use. The third principle is the use of ecologically benign materials. All possible measures are to be taken to use building materials and products that minimize destruction of the global environment, wood is to be selected based on non destructive forestry practices and other materials and products are to be considered based on the toxic waste output of production. The fourth principle is Environmental Form. All possible measures are to be taken to relate the form and plan of the design to the site, the region and the climate and measures are to be taken to "heal" and augment the ecology of the site. Accommodations are to be made for recycling and energy efficiency and measures are to be taken to relate the form of building to a harmonious relationship between the inhabitants and nature. The fifth principle is good design. All possible measures are to be taken to achieve an efficient, long lasting and elegant relationship of use areas, circulation, building form, mechanical systems and construction technology, symbolic relationships with appropriate history, the earth and spiritual principles are to be searched for and expressed, and finished buildings shall be well built, easy to use and beautiful. Many definitions of a sustainable community have been put forward, but they all revolve around the interconnectedness of society, economy and environment; a sustainable community is one in which the economic, social and environmental systems that make up the community provide a healthy, productive, meaningful life for all community residents, present and future. Sustainable communities acknowledge that there are limits to the natural, social and built systems upon which we depend [5]. 


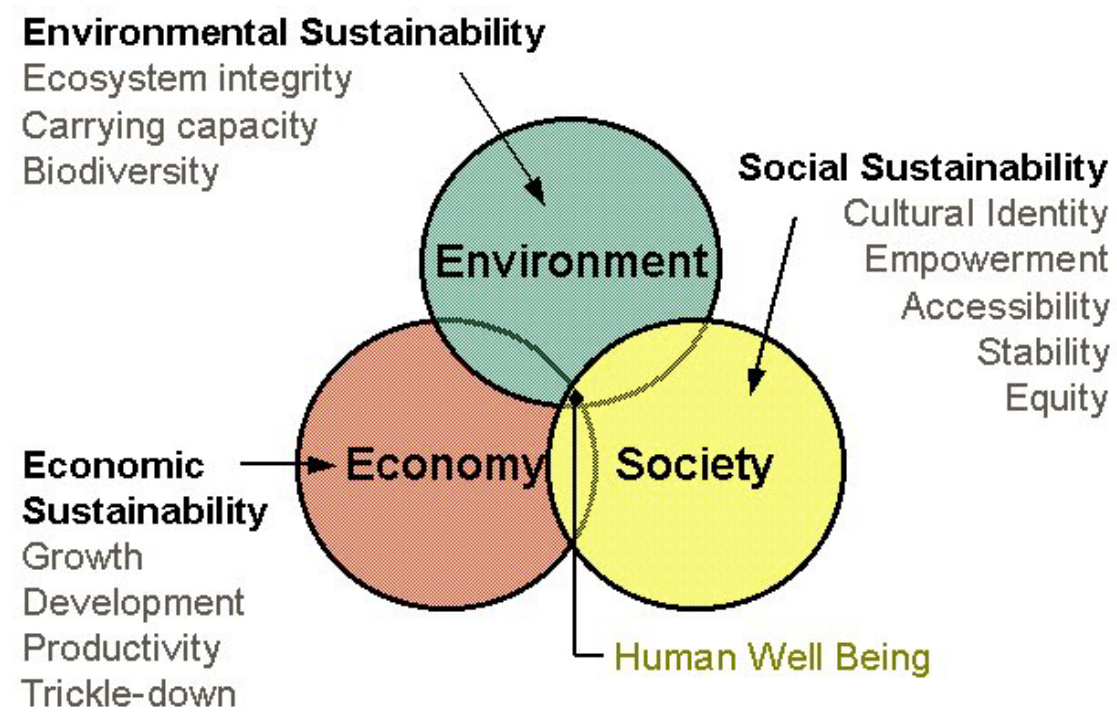

Figure 1: $\quad$ Three dimensions of sustainability.

In addition to social, economic, and environmental health, sustainable communities are about the participation of all elements of society in decisionmaking processes. Local governments can help their communities to become more sustainable, but they cannot do it without a mandate from, and the participation of the local community, according to the National Round Table on the Environment and the Economy. Sustainability must be community-led and consensus-based because the central issue is will, not expertise; only a community-based process can overcome the political, bureaucratic and psychological barriers to change. However, citizen-led processes must be complemented by top-down government support because it is still only governments that have the regulatory powers to secure the transition to sustainable development.

\subsection{Model principles for sustainable communities}

A sustainable community is one that recognizes that growth occurs within some limits and is ultimately limited by the carrying capacity of the environment. It values cultural diversity, has respect for other life forms and supports biodiversity and has shared values amongst the members of the community, (business and personal decision-making processes). The community makes decisions and plans in a balanced, open and flexible manner that includes perspectives from the social, health, economic and environmental sectors of the community. It makes best use of local efforts and resources (nurtures solutions at the local level) and uses renewable and reliable sources of energy. It minimizes harm to the natural environment, fosters activities that use materials in continuous cycles and, as a result, a sustainable community does not compromise the sustainability of other communities [6]. 


\section{Social impact assessment methodology}

The impacts of development interventions take different shapes. While significant benefits flow forth from different development actions, there is a need to also identify and evaluate the associated negative externalities. Social impacts are impacts of developmental interventions on human settlements; such impacts not only need to be identified and measured but also need to be managed in such a way that the positive externalities are magnified and the negative ones minimized. This document provides a realistic methodology for appraisal of possible social ramifications through active stakeholder participation and their effective mitigation.

\subsection{Social impact assessment (SIA) definition}

Social impact assessment (SIA) is the process of assessing and managing the impacts of a project, plan, program or policy on people. Although there has been some debate over the precise meanings of terms such as SIA, Social Analysis, Social Assessment, Social Appraisal, and even Social Soundness Analysis, most of the debate about these terms has had little bearing on the SIA discipline. Amongst the international professional community interested in SIA, although there is not a generally agreed definition, I will define that concept as: "Social impact assessment is the process of analysing and managing the intended and unintended consequences on the human environment of interventions (policies, plans, programs, projects and other social activities) and social change processes so as to create a more sustainable biophysical and human environment" [7].

\subsection{SIA important features and variables}

SIA is understood to include adaptive management of impacts, projects and policies and therefore needs to be involved (at least considered) in the planning of the project or policy from inception. The SIA process can be applied to a wide range of interventions, and undertaken at the behest of a wide range of actors, and not just within a regulatory framework; it is implicit that social and biophysical impacts are interconnected; and finally, the overall purpose of all impact assessment is to bring about a more sustainable world, and that issues of social sustainability and ecological sustainability need to be considered in partnership. SIA variables point to measurable change in human population, communities, and social relationships resulting from a development project or policy change. After research on local community change, rural industrialization, reservoir and highway development, natural resource development, and social change in general, we suggest a list of social variables under the general headings of: population characteristics, community and institutional structures, political and social resources, individual and family changes, and community resources [8].

\section{Eco-architecture winning projects}

The AKDN through its efforts gifts architectural awards for sustainable and ecoarchitectural projects that seek to identify and encourage building concepts that 
successfully address the needs and aspirations of societies in which Muslims have a significant presence. The selection process emphasizes architecture that not only provides for people's physical, social and economic needs, but that also stimulates and responds to their cultural and spiritual expectations. Particular attention is given to building schemes that use local resources and appropriate technology in an innovative way and to projects likely to inspire similar efforts elsewhere and this paper will analyze three of the winning projects for the 2007 cycle [9].

\subsection{Royal Netherland Embassy, Addis Ababa, Ethiopia}

The Royal Netherlands Embassy complex lies amidst the urban sprawl on the southern outskirts of Addis Ababa, enclosed within a dense eucalyptus grove. The architects' guiding principle was to preserve and respect the topography of the surrounding landscape while addressing the functional requirements of a working embassy. They took care to maintain existing contour lines and leave the vegetation and wildlife undisturbed. The main building, an elongated horizontal volume, cuts across the sloping terrain on an east-west axis. Walls, floors and ceilings are pigmented the same red-ochre as the Ethiopian earth and are uniformly composed of concrete, creating the effect of a cave-like space, reminiscent of the rock-hewn architecture of Ethiopia. By contrast, the roof garden with its network of shallow pools alludes to a Dutch water landscape. An unashamedly contemporary and simple organisation of spaces, the Dutch Embassy in Addis Ababa overcomes the complexities of security and surveillance normally associated with the design of embassy compounds. It is a quiet yet superbly imaginative intervention into the existing landscape, and the sensitivity to place and process is abundantly clear in this space of encounter between traditional Ethiopian architecture and Dutch cultural and architectural themes.

\subsection{School in Rudrapur, Dinajpur, Bangladesh}

This joyous and elegant two-storey primary school in rural Bangladesh has emerged from a deep understanding of local materials and a heart-felt connection
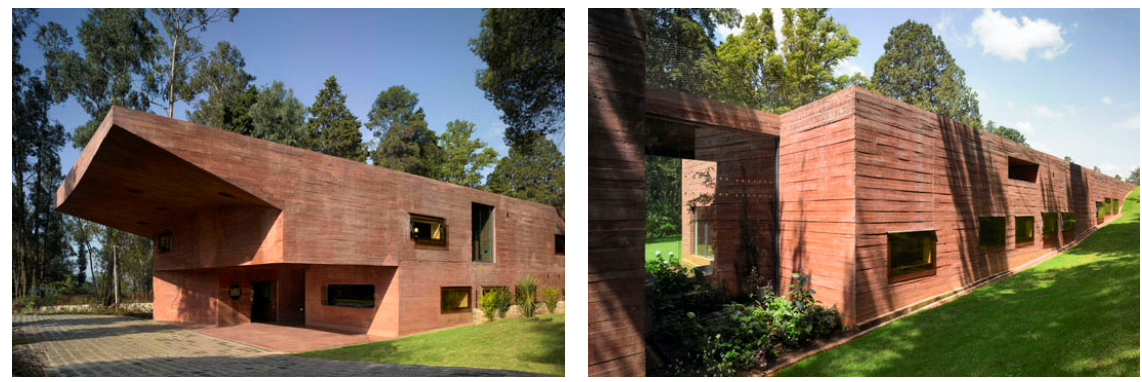

Figure 2: The Royal Netherland Embassy. 
to the local community. Hand-built in four months by local craftsmen, pupils, parents and teachers together with experts from Germany and Austria, it uses traditional methods and materials of construction but adapts them in new ways to create light-filled beautiful, meaningful and humane collective spaces for learning. The school is part of the Modern Education and Training Institute (METI) of the Bangladeshi NGO Dipshikha, which places an emphasis on helping children develop their own potential and use it in a creative way. The building follows the same principles, bringing out the best in local materials by inventively combining them with improved construction techniques. Earthbound materials such as loam and straw are combined with lighter elements like bamboo sticks and nylon lashing to shape a built form that addresses sustainability in construction in an exemplary manner.
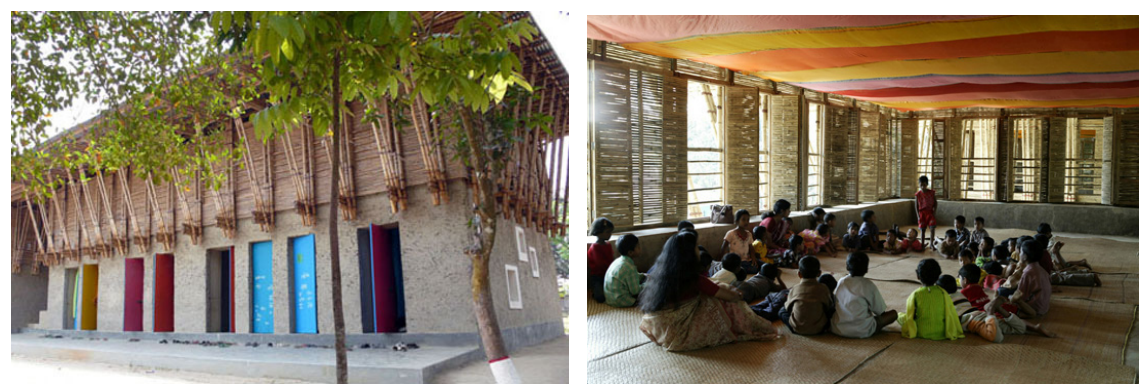

Figure 3: The Bangladesh school in Rudrapur.

\subsection{University of Technology Petronas, Malaysia}

The University of Technology Petronas' prototypical built configuration, consisting of an all-encompassing shaped canopy with functional boxes inserted underneath, is a contemporary reinterpretation of the classic metaphor for tropical architecture - an umbrella that offers protection from the sun and rain. It is a complex educational structure that links concept with expectation, its hightech emblematic architecture appropriate for a large scientific university in a rapidly developing nation. At the same time, the design responds both to the physical landscape and to the weather patterns of the Malay peninsula. A soaring, crescent-form roof supported by steel columns winds around the edge of the site, covering pedestrian routes and providing a defined, shaded zone for social interaction and circulation. To preserve the natural topography, the core academic buildings are wrapped around the base of a series of knolls, and viewed from a distance, the university's canopy elevation echoes the tree canopy of the densely forested site. This is an exemplary use of a performance-based approach to architectural design that goes beyond the diagram. The design has been carried through to completion with meticulous detail, rigour and persistence, and marks a real collaboration between the two architectural practices, with an important transfer of knowledge, process and technology. 

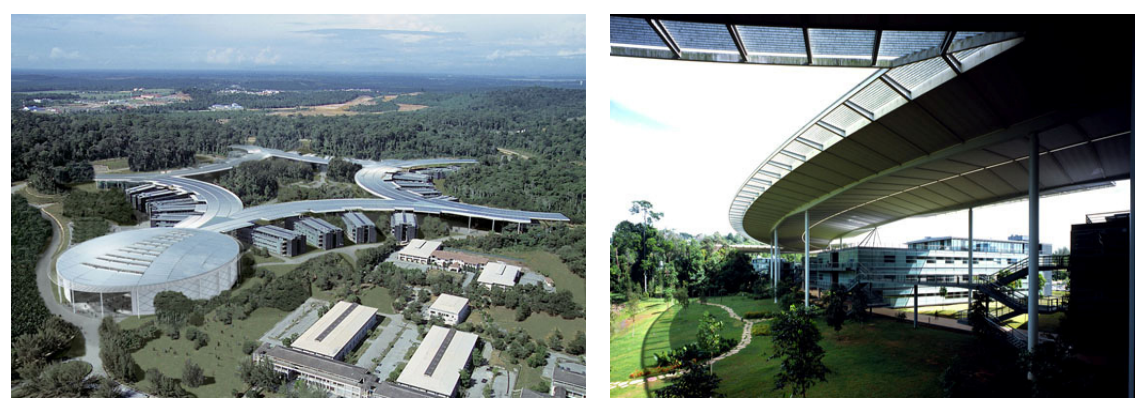

Figure 4: University of Technology, Malaysia.

\section{Achieving eco-architecture building}

An ecological approach to the built environment involves a holistic approach to the design of buildings. All the resources that go into a building are by materials, fuels or the contribution of the users need to be considered if a sustainable architecture is to be produced. Producing ecological buildings involves resolving many conflicting issues and requirements. Each design decision has environmental and social implications. Measures for ecological buildings can be divided into four areas, reducing energy in use, minimising external pollution and environmental damage reducing embodied energy and resource depletion, minimising internal pollution and damage to health. An ecological building places a high priority on health, environmental and resource conservation performance over its life-cycle. These new priorities expand and complement the classical building design concerns: economy, utility, durability, and delight. green design emphasizes a number of new environmental, resource and occupant health concerns, Reduce human exposure to noxious materials, conserve nonrenewable energy and scarce materials, minimize life-cycle ecological impact of energy and materials used, use renewable energy and materials that are sustainably harvested, protect and restore local air, water, soils, flora and fauna, support pedestrians, bicycles, mass transit and other alternatives to fossil-fuelled vehicles. Most ecological buildings are high-quality buildings; they last longer, cost less to operate and maintain, and provide greater occupant satisfaction than standard developments. What surprises many people unfamiliar with this design movement is that good ecological buildings often cost little or no more to build than conventional designs. Commitment to better performance, close teamwork throughout the design process, openness to new approaches, and information on how these are best applied are more important than a large construction budget. Ecological building needs to fulfil the six issues mentioned table 1 [8].

Table 1: $\quad$ The six issues to be considered in eco-architecture.

\begin{tabular}{|c|c|c|}
\hline Site & Energy & Water \\
\hline Materials & Waste & Community \\
\hline
\end{tabular}




\subsection{Site issues}

Considering ecological building we have to mention the site issue that will contain landform and microclimate (topography, light-coloured surfacing, vegetative cooling, wind buffering and evaporative cooling), land-use (use density, use mix and activity concentration), site design (solar orientation, pedestrian orientation), infrastructure efficiency (water supply and use, waste water collection, storm drainage, street lighting and recycling facilities), and finally on-site energy resources.

\subsection{Energy issues}

The benefits from the energy-efficient siting and design of buildings are economic (saving money), social (reducing fuel poverty); and ecological (reducing resource exploitation and emissions). Every new development ideally should have an explicit energy strategy, setting out how these benefits are to be achieved.

\subsection{Water issues}

Water conservation methods: Toilets (Low flush toilets, dual flush toilets, vacuum or compressed air toilets cistern displacement devices, waterless toilets (composting toilets, incinerating toilets), wash hand basins (push taps, flow control, self closing, tap flow regulators), outside and garden.

\subsection{Material issues}

The energy input required to quarry, transport and manufacture building materials, plus the energy used in the construction process, can amount to a quarter of the 'lifetime' energy requirement of a very energy-efficient building. To reduce embodied energy, without compromising longevity or efficiency: reuse existing buildings and structures wherever possible (provided their energy costs in use can be reduced to an acceptable level), design buildings for long life, with ease of maintenance and adaptability to changing needs, construct buildings and infrastructure out of local and low- energy materials where possible, reduce the proportion of high rise, detached or single-storey developments, design layouts which minimise the extent to roadway and utility pipe work per dwelling.

\subsection{Waste issues}

Humans are the only species on Earth that produce waste which is not a raw material or nutrient for another species. We are the only species to produce wastes that can be broadly toxic and build up for long periods of time. As William McDonough, Dean of the University of Virginia School of Architecture, has said, a sustainable society would eliminate the concept of waste. Waste is not simply an unwanted and sometimes harmful by-product of life; it is a raw material out of place. Waste and pollution demonstrate gross inefficiency in the 
economic system since they represent resources that are no longer available for use and/or create harm in humans and other species [10].

\subsection{Community issues}

Many definitions of a sustainable community have been put forward, but they all revolve around the interconnectedness of society, economy and environment, a sustainable community is one in which the economic, social and environmental systems that make up the community provide a healthy, productive, meaningful life for all community residents, present and future. Sustainable communities acknowledge that there are limits to the natural, social and built systems upon which we depend. In addition to social, economic, and environmental health, sustainable communities are about the participation of all elements of society in decision-making processes. Local governments can help their communities to become more sustainable, but they cannot do it without a mandate from, and the participation of the local community.

\section{Conclusion}

Eco-architecture must be community-led and consensus-based because the central issue is will, not expertise; only a community-based process can overcome the political, bureaucratic and psychological barriers to change. However, citizen-led processes must be complemented by top-down government support because it is still only governments that have the regulatory powers to secure the transition to sustainable development, and here is the role of social impact assessment which is predicated on the notion that decision-makers should understand the consequences of their decisions before they act, and that the people affected will not only be apprised of the effects, but have the opportunity to participate in designing their future.

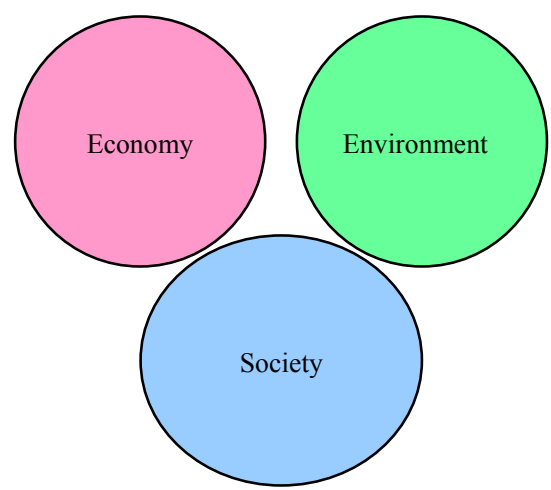

Figure 5: A view of community as three separate, unrelated parts: an economic part, a social part and an environmental part. Traditional quality of life indicators tend to measure these three parts separately. 


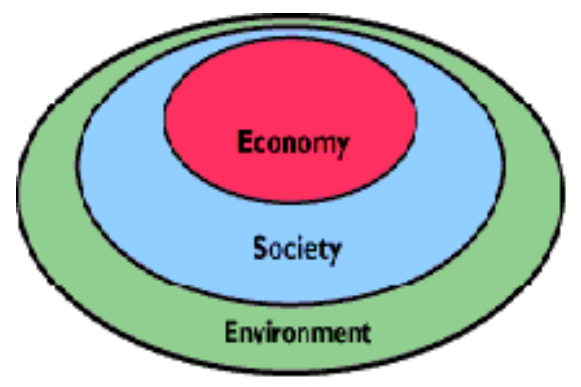

Figure 6: A view of community as three concentric circles: the economy exists within society, and both the economy and society exist within the environment. Sustainability indicators attempt to measure the extent to which these boundaries are respected.

\section{References}

[1] F. J. Soria López, Architecture and nature at the end of the 20th century: towards a dialogical approach for sustainable design in architecture. Proc. of the 1st Int. Conf. On Harmonisation between Architecture and Nature, G. Broadbent, New Forest, UK, pp.24-28, 2006.

[2] Wikipedia encyclopaedia web site, http://en.wikipedia.org/wiki/Sustainable architecture\#Sustainable_building_materials

[3] Building Energy Efficiency Research web site, http://www.arch.hku.hk/ research/beer/sustain.htm\#1.1

[4] Sustainable Buildings, Low Energy Housing. The European Sustainable Energy Systems in Advanced Cities (SESAC) web site, http://www.concerto-sesac.eu/spip.php?rubrique81

[5] Foster, Norman, The Economy of Architecture, in Back from Utopia: The Challenge of the Modern Movement. Rotterdam: 010 Publishers, pp. 26-37, 2002.

[6] Markiewiscz, Evan, Architecture, Society and Social Change, in ArcCA: the journal of the American Institute of Architects, California Council, no. 2, pp. 42-45, 2003.

[7] Taylor CN, Bryan CH, Goodrich CG, Social Assessment: theory, process and techniques, Middleton, WI: The Social Ecology Press, pp.15-22, 2004.

[8] Global Sustainability Concepts: Capital \& Subsidies. UNCED and Rio web site, http://darwin.bio.uci.edu/ sustain/state/chapter1.htm

[9] Aga Khan Award for Architecture web site: http://78.136.16.169/ pages/p03124.html

[10] Dennis A. Rondinelli \& Michael A. Berry, Environmental citizenship in multinational corporations: social responsibility and sustainable development, European Management Journal, volume 18, Issue 1, pp. 70$84,2000$. 